\title{
En reclamo de un resarcimiento: trabajadores y accidentes de trabajo en Buenos Aires (1900-1915)
}

\author{
Florencia D’ Uva \\ Universidad Nacional de Buenos Aires
}

\begin{abstract}
Resumen
Este artículo se propone examinar algunas demandas judiciales iniciadas por trabajadores -o sus familiares- para obtener una indemnización que resarciera los daños y perjuicios ocasionados a raíz de un accidente de trabajo. Se interesa puntualmente por desentrañar qué nociones de justicia se pusieron en práctica en estas demandas, así como rastrear las estrategias que los peticionarios desplegaron para conseguir un dictamen favorable. Los Boletines publicados por el Departamento Nacional del Trabajo entre 1907 y 1915 -año de la sanción de la Ley $n^{\circ} 9.688$ de Accidentes de Trabajo- constituyen la fuente principal de este trabajo.
\end{abstract}

\section{Palabras clave:}

Trabajadores, accidentes, demandas, justicia, estrategias

\begin{abstract}
This paper seeks to analyze some lawsuits initiated by workers -or their families- in order to get a compensation to repair damages caused by an occupational accident. Specifically, it is interested in unravel which notions of justice played a role in worker's lawsuits, as well as to discover some of the strategies deployed to obtain a favourable court ruling. The newsletters published by the Departamento Nacional del Trabajo between 1907 and 1915 -year in which the occupational accident law was sanctioned- constitutes the main source of this article.
\end{abstract}

Key words:

Workers, accidents, demands, justice, strategies 


\section{En reclamo de un resarcimiento}

\section{Introducción}

Fallo, condenando al demandado Don enrique Fynn, á abonar dentro del término de diez días al demandante, Don José Orlando, la suma que este jure adeudársele dentro de la de quince mil pesos moneda nacional fijada por el juzgado á los efectos del juramento estimatorio ordenado, con costas á cargo del mismo demandado por formar parte ellos del daño causado (...).

Boletín del Departamento Nacional del Trabajo n 16, Marzo 31 de 1911, p. 60.

El 21 de diciembre de 1909, el herrero José Orlando ganó el juicio iniciado varios años atrás, luego de accidentarse mientras trabajaba en un taller de herrería propiedad de Enrique Fynn. A raíz del accidente, producido en abril de 1905, el demandante había sufrido la amputación de una pierna a la altura de la rótula. Ante el pedido del herrero accidentado, el empleador prometió indemnizarlo en un futuro cercano y, mientras tanto, continuó dándole trabajo, aunque reduciendo su jornal en casi un cincuenta por ciento. Luego de realizar diversas gestiones para conseguir la indemnización, sin éxito, José Orlando inició una demanda judicial para reclamar el resarcimiento que consideraba justo, de acuerdo al daño recibido, que según afirmaba, lo imposibilitaba para toda la vida. Como resultado, el empleador fue sentenciado a pagar una indemnización consistente en una suma de dinero estipulada en base a la edad de la víctima, la naturaleza de la lesión sufrida y la utilidad dejada de percibir 1 .

El caso arriba mencionado no fue una excepción en la Buenos Aires de principios de siglo XX, donde los accidentes de trabajo se multiplicaban al ritmo del crecimiento industrial. Fueron varios los trabajadores (o familiares, cuando el incidente resultaba mortal o el accidentado era menor de edad) que acudieron a la Justicia para reclamar una indemnización que compensara los daños sufridos. Como se verá a lo largo de este artículo, a veces la conseguían, aunque nada estaba asegurado de antemano y el fallo variaba según las particularidades de cada caso, las estrategias de los abogados, el juzgado en el que era presentado y el juez que se hiciera cargo de la causa, entre otros tantos factores que podían influir en el desarrollo y resultado de la contienda.

Los estudios que han analizado la cuestión de los accidentes de trabajo, se han centrado mayormente en el análisis de la ley número 9.688 sancionada en 1915. Los primeros análisis, provenientes de una línea historiográfica que buscaba reconstruir las condiciones materiales de vida y trabajo de la clase obrera de principios del siglo pasado, hicieron hincapié en los antecedentes y debates previos a la aprobación de la ley2. Posteriormente, surgieron investigaciones que analizaron el rol de los magistrados en las demandas judiciales iniciadas

\footnotetext{
${ }^{1}$ Boletín del Departamento Nacional del Trabajo (BDNT), N 16, 1911, pp. 56-62.

2 José Panettieri. Las primeras leyes obreras, Buenos Aires, CEAL, 1984; Ernesto Isuar. Los orígenes conflictivos de la seguridad social argentina. Buenos Aires, CEAL, 1985.
} 


\section{Florencia D'Uva}

previamente a la sanción de la ley33, así como la perspectiva de los médicos y juristas y las modificaciones e implementación de la ley desde su sanción hasta mediados del siglo XX4. Desde hace unos años, el interés por el tema me motivó a ensayar algunas aproximaciones y acercamientos a la problemática explorando los debates y propuestas parlamentarias, las acciones emprendidas por el Partido Socialista y por los propios trabajadores que fueron abriendo el camino a la sanción de la ley5.

En un intento por alejar el foco de análisis del marco legal, sus antecedentes y consecuencias, para situarlo en las acciones emprendidas por los propios damnificados, este artículo se interesa por analizar algunos fallos dictados en causas judiciales iniciadas por trabajadores, o sus familiares, a raíz de un accidente de trabajo durante los años previos a la promulgación de la ley. Su objetivo es desentrañar algunas de las nociones de justicia que se pusieron en práctica en las demandas judiciales iniciadas por los trabajadores, así como algunas de las estrategias que éstos desplegaron para conseguir un dictamen favorable. Toma como referencia a las investigaciones provenientes del campo de la Historia Social de la Justicia, inscriptas en una agenda historiográfica común a distintos países latinoamericanos, que han reconstruido las acciones judiciales emprendidas por distintos grupos sociales con escasos derechos formales ${ }^{6}$. Estas producciones mostraron cómo quienes acudieron a la Justicia se apropiaron de nociones de derecho y leyes ofrecidas por el Estado, reinterpretándolas y resignificándolas para su propio provecho. En especial, el estudio de Larissa Corrêa para el caso de los obreros metalúrgicos y tejedores de San Pablo a mediados de siglo XX, reveló cómo la ley pudo ser un instrumento de lucha para los trabajadores, en lugar de pensarla como una herramienta al servicio de las clases dominantes7. Para ello, la

\footnotetext{
${ }^{3}$ Line Schjolden. "Sentencing the Social Question: Court-Made Labour Law in Cases of Occupational Accidents in Argentina, 1900-1915”. Journal of Latin American Studies, n 41, 2009, pp. 91-120.

${ }^{4}$ Karina Ramacciotti. "De la culpa al seguro. La Ley de Accidentes de Trabajo, Argentina (19151955)”. Mundos do Trabalho, 3(5), 2011, pp. 266-284; Karina Ramacciotti, “¿Soldados del trabajo o ciudadanos? La Ley de Accidentes de Trabajo en la Argentina, 1915-1955"; en Mirta Lobato y Juan Suriano (comp.). La sociedad del trabajo. Las instituciones laborales en la Argentina (1900-1955). Buenos Aires Edhasa, 2014.

${ }^{5}$ Florencia D’Uva y Ludmila Scheinkman. "De lisiadas y tullidos. Trabajadoras y trabajadores ante la Ley de Accidentes de Trabajo de 1915". Ponencia presentada en el Congreso Latinoamericano de Historia de las Mujeres, Buenos Aires - San Juan, 2012; "Rotos y mal parados: los trabajadores ante la sanción de la ley de Accidentes de Trabajo de 1915”. Actas de las 3ras Jornadas Internacionales de Problemas Latinoamericanos: Movimientos Sociales, Estados y Partidos Políticos en América Latina: (re)configuraciones institucionales, experiencias de organización y resistencia. Publicación Electrónica, Mendoza, 2012; "La ley de Accidentes del Trabajo en Argentina: la demanda de los trabajadores (1915)", ponencia presentada en las XIV Jornadas Interescuelas/Departamentos de Historia, Universidad Nacional de Cuyo, Mendoza, 2013.

6 Silvia Lara e Joseli Mendonça (et.al.). Direitos e Justicas no Brasil: ensaios de história social. Unicamp, Ed. Unicamp, 2006; Lyman Johnson. "A lack of legitimate Obedience and Respect: Slaves and their Masters in the Courts of Late Colonial Buenos Aires". Hispanic American Historical Review, 87, (4), 2007; Larissa R. Corrêa. A tessitura dos direitos: patrões e empregados na Justiça do Trabalho, 1953-1964. San Pablo, Editora Ltda., 2011.

${ }^{7}$ Es necesario aclarar que esto no se tradujo en la anulación de otras vías e instancias de reclamo y protesta, sino que por el contrario, como varios estudios demuestran, el reclamo en la Justicia convivió con otras formas de reclamar derechos que se desarrollaron por fuera del ámbito judicial
} 


\section{En reclamo de un resarcimiento}

autora partió de un diálogo historiográfico con E.P. Thompson, quien en su célebre estudio sobre la ley negra en la Inglaterra del siglo XVIII evidenció el carácter complejo y ambiguo de las leyes y sus usos ${ }^{8}$. Es siguiendo el camino abierto por estos estudios que la presente pesquisa intenta avanzar.

Para lograr su objetivo, este artículo realiza un minucioso análisis de los Boletines publicados por el Departamento Nacional del Trabajo entre 1907 y 1915 que, además de brindar información estadística sobre accidentes, reprodujeron varias sentencias judiciales en las que se pueden rastrear las huellas de las voces de los trabajadores. En estas, las declaraciones de los demandantes -y demandados- aparecen de manera indirecta en los considerandos del juez, lo que limita la información disponible sobre quiénes eran los que iniciaban el litigio, cómo se presentaban a sí mismos y a los hechos, sus pretensiones y argumentos. Igualmente, una lectura a contrapelo de los fallos posibilita advertir qué ponían en juego para conseguir lo que buscaban y cómo intentaban articular un argumento sólido que demostrara que eran merecedores de un resarcimiento. Pero, también, permite reconstruir parte de la vida de esos trabajadores y sus familias, quienes en un momento de su vida se presentaron ante la Justicia y expresaron quiénes eran, dónde y cómo trabajaban, qué les había ocurrido que los motivaba a litigar, qué pretendían recibir a raíz de los daños y perjuicios sufridos, entre otras cuestiones. Al hacerlo, asumían un rol particular, situándose como trabajadores y como sujetos de derechos ${ }^{10}$.

La primera parte del artículo se adentra en los Boletines publicados por el DNT desde 1907 hasta 1915 e indaga en las estadísticas e informes elaborados por sus funcionarios, buscando entrever cuáles fueron las principales preocupaciones y objetivos que guiaron la confección de los datos. En la segunda parte, el análisis se centra en las acciones entabladas por los propios trabajadores, intentando seguir la pista que estos dejaron en la Justicia y conocer los móviles, expectativas y nociones sobre lo justo que se pusieron en juego en las estrategias elaboradas para conseguir lo que consideraban un derecho.

(Silvana Palermo. “'Trabajo masculino, protesta femenina? La participación de la mujer en la gran huelga ferroviaria de 1917"; en María Celia Bravo, (et al.). Historias de luchas, resistencias y representaciones. Mujeres en la Argentina, siglos XIX y XX, Tucumán, EDUNT, 2007; S. Pita. La Casa de las Locas. Una historia social del manicomio de mujeres. Buenos Aires 1852-1890. Rosario, Prohistoria, 2012).

8 Edward P. Thompson. Los orígenes de la Ley Negra. Un episodio de la historia criminal inglesa. Buenos Aires, Siglo Veintiuno editores, 2010.

9 Hay que tener en cuenta que los fallos judiciales citados por el DNT están publicados en sus Boletines porque, por algún motivo, adquirieron cierta notoriedad para los funcionarios que elaboraron los informes sobre la jurisprudencia argentina en materia de accidentes de trabajo.

10 Sobre el tema de la construcción de la ciudadanía y los derechos políticos ver Hilda Sábato. $L a$ política en las calles. Entre el voto y la movilización. Buenos Aires, 1862-1880. Buenos Aires, Editorial Sudamericana, 1998; Hilda Sábato (coord.). Ciudadanía y formación de las naciones. Perspectivas históricas de América Latina. México, Fondo de Cultura Económica, 1999; Silvana Palermo, "Género y ciudadanía política: algunos apuntes en la agenda de investigación". PolHis, $\mathrm{N}^{\circ} 7,1^{\circ}$ semestre de 2011. 


\section{Florencia D'Uva}

\section{Accidentes de Trabajo y Seguro obrero en la Ciudad de Buenos Aires: la construcción de la información.}

A principios del siglo XX, la Argentina atravesaba una etapa de crecimiento, caracterizada por el aumento poblacional generado por la inmigración, el desarrollo de industrias incipientes, el crecimiento de las ciudades, la aparición de nuevos sectores sociales y de nuevas formas de organización entre los cada vez más numerosos sectores trabajadores. Estos cambios implicaron efectos no deseados que concitaron la atención de las clases dominantes ${ }^{11}$. De manera particular, el trabajo y las nuevas relaciones laborales, fueron convirtiéndose en un nudo problemático que impulsó la aparición de políticas e instituciones específicas, que buscarían regular las relaciones entre el capital y el trabajo12. Con este propósito, en 1907 se creó el Departamento Nacional del Trabajo (DNT). Este organismo estatal, por medio de un elenco de funcionarios y profesionales especializados, realizó detallados estudios, estadísticas e inspecciones con el objetivo de conocer la realidad del mundo del trabajo en la Argentina de principios de siglo. Dentro de esta realidad, los accidentes de trabajo, entre otros tópicos, constituían un problema que preocupaba a diversos sectores sociales. Esto último se evidencia en los múltiples proyectos de ley que fueron presentados en el Congreso entre 1902 y 1915³, así como en la gran cantidad de veces que el tema fue abordado en los Boletines del DNT entre 1907 y la sanción de la ley de Accidentes en 1915. A su vez, el tema fue objeto de atención de diversos gremios y organizaciones partidarias y político-ideológicas del movimiento obrero, que por medio de sus periódicos y boletines de propaganda se expresaban al respecto ${ }^{14}$.

\footnotetext{
${ }^{11}$ La llamada "cuestión social" (término con el que se denominaba a las consecuencias sociales negativas ocurridas a partir de las transformaciones que atravesaba la Argentina entre fines del siglo XIX y comienzos del XX) generó variadas reacciones en la clase dirigente que, para intentar solucionar los crecientes conflictos sociales, ensayó distintas respuestas. Algunas apuntaban a reprimir y excluir los elementos considerados "disruptivos" del orden social, mientras que otras buscaban mejorar las condiciones de vida y trabajo de vastos sectores de la población, con el propósito de prevenir el malestar social. Para adentrarse en distintas interpretaciones sobre este tema, ver Eduardo A. Zimmermann. Los liberales reformistas. La cuestión social en la Argentina 1890-1916. Buenos Aires, Editorial Sudamericana, Universidad de San Andrés, 1995; Juan Suriano. La cuestión social en Argentina 1870-. 1943. Buenos Aires, La Colmena, 2000.

12 Mirta Lobato y Juan Suriano (comp.). La sociedad del trabajo. Las instituciones laborales en la Argentina (1900-1955). Buenos Aires, Edhasa, 2014.

13 Entre 1902 y 1915 se presentaron en el Congreso Nacional numerosos proyectos de ley sobre Accidentes de Trabajo formulados por los diputados B. Roldán y M.M. Avellaneda (1902), el Poder Ejecutivo (1904 y 1910), la Unión Industrial Argentina (1906), los diputados socialistas (1907 y 1910), el DNT (1907) y Dr. A. C. Escobar (1910). Durante estos años surgieron múltiples proyectos de ley -algunos de los cuales fueron sancionados- que buscaban proteger a los trabajadores frente a circunstancias particulares (como accidentes de trabajo), o simplemente mejorar las condiciones en las que ejercían su labor.

14 Para mayor información sobre el accionar de estas organizaciones, principalmente del Partido Socialista, ver D’Uva y Scheinkman Op. Cit., 2012. Como ejemplo del interés que este problema generaba en los gremios, pueden consultarse algunos periódicos sindicales de la primera y segunda década del siglo XX. Como parte de otro estudio, he consultado los órganos de propaganda de los gremios ferroviarios La Fraternidad y Federación Obrera Ferrocarrilera, en cuyas páginas pueden leerse varias noticias sobre trabajadores accidentados, y distintos reclamos al respecto.
} 


\section{En reclamo de un resarcimiento}

Al crearse el DNT en 1907, la información sobre el mundo del trabajo en la Argentina era escasa y fragmentaria ${ }^{15}$. Este organismo inició un estudio sistemático sobre las condiciones de trabajo, que redundó en detallados informes que hoy constituyen una valiosa fuente que puede ser indagada desde múltiples preguntas y perspectivas. Una de las funciones del DNT era la confección de estadísticas sobre cuestiones o problemas puntuales que se consideraba que había que estudiar y conocer para poder elaborar políticas al respecto. Desde su fundación, varios números de sus Boletines dedicaron decenas de páginas al tema de los accidentes de trabajo, brindando información variada y recopilando la jurisprudencia nacional y extranjera al respecto. De hecho, el Boletín número 20 del año 1912 estuvo enteramente dedicado al tema, elección justificada "por el crecido número de proyectos de ley que en todo tiempo se han presentado a la consideración del Congreso Argentino"16.

A partir de las estadísticas confeccionadas por el DNT se puede obtener información sobre diversos aspectos de los accidentes de trabajo así como sobre cuáles eran las principales preguntas y preocupaciones de los contemporáneos al estudiar el tema. Siguiendo a Hernán Otero, las estadísticas pueden ser pensadas como "producción intelectual que testimonia las concepciones intelectuales y políticas de sus autores o de una época"17. Según este autor, el discurso estadístico no es una percepción objetiva del mundo social, sino que en él intervienen variados procesos que modelan y afectan la construcción del objeto mismo18. Partiendo de esta concepción, las estadísticas elaboradas por el DNT pueden ser abordadas teniendo en cuenta tanto los datos cuantitativos que ofrecen sobre un asunto puntual, en este caso los accidentes de trabajo, como la información implícita que ellas contienen y que tiene que ver más con el contexto en el que fueron producidas. Esto último refiere a los métodos, técnicas e instrumentos de medición utilizados para su confección, al rol de los estadísticos, sus conocimientos, su relación con las instituciones de gobierno, su margen de acción y al contexto social, económico y político en el que se desenvolvieron, entre otras cuestiones. Si bien el análisis de estos factores escapa al objeto de este estudio, resulta importante tener esta cuestión presente para evitar la tentación de interpretar los datos como un fiel reflejo de la realidad.

El primer Boletín del DNT que contenía información sobre los accidentes de trabajo en la Ciudad de Buenos Aires fue el número 2, correspondiente a septiembre de 190719. Varias notas reproducidas en este número, enviadas por el

\footnotetext{
15 Juan Suriano, “El mundo como un taller de observación. La creación del Departamento Nacional del trabajo y las influencias internacionales”. Revista de Indias; vol. LXXIII, n 257, 2013.

${ }^{16} B_{D N T} \mathrm{n}^{\circ} 20,1912$, p. 3

17 Hernán Otero. Estadística y Nación. Una historia conceptual del pensamiento censal de la Argentina moderna (1869-1914). Buenos Aires, Prometeo, 2007, p. 34.

18 Ibíd., p. 35.

19 Este número también publicaba el proyecto de ley sobre reparación de los accidentes de trabajo elaborado por el DNT en base a la información recopilada por este organismo respecto a las prácticas de la Argentina, los proyectos ya presentados, y las leyes vigentes en distintos países
} 


\section{Florencia D'Uva}

presidente del organismo, José Nicolás Matienzo, a distintas instituciones y funcionarios (como la Unión Industrial Argentina -UIA-, el Jefe de Policía y el Intendente municipal de la Capital Federal), brindan pistas para conocer cómo comenzaban a elaborarse las estadísticas relativas a los accidentes de trabajo y al seguro contra los mismos. Con respecto a este último, Matienzo solicitaba a la UIA información puntual: el número de establecimientos industriales que aseguraban a sus obreros contra accidentes, los montos y principales clausulas del seguro, los posibles inconvenientes con las aseguradoras $\mathrm{y}$, si existían, las formas alternativas de indemnización. A partir de los datos reunidos, se elaboraron varios cuadros estadísticos sobre los seguros contra accidentes vigentes al 30 de junio de 1907, que contenían información brindada por cuatro compañías aseguradoras sobre la cantidad de pólizas, de obreros asegurados y de siniestros ocurridos 20 .

En relación a los accidentes de trabajo, en las notas enviadas a la Policía y a la Intendencia municipal de la Capital Federal, Matienzo pedía el envío mensual de datos sobre el tema para facilitar la elaboración de una estadística al respecto (que contemplaría también a las enfermedades contraídas en el trabajo). Se solicitaba detallar la edad, nacionalidad, sexo, oficio, naturaleza de la lesión sufrida, tiempo de asistencia, resultado y naturaleza de la incapacidad adquirida (si es que la hubiera), así como la clase del establecimiento en que se había adquirido la enfermedad o producido el accidente ${ }^{21}$. A continuación, se publicaba un cuadro con los accidentes de trabajo en la Ciudad de Buenos Aires durante julio y agosto de 1907. Según las distintas profesiones (por ejemplo: panaderos, herreros, caldereros, cigarreros, etc.) se especificaba el daño recibido (muerte, lesión leve o grave $^{22}$ ), la edad (menores de 14 años, 14 a 20, 20 a 30, 30 a 40, 40 a 50, 50 a 60,

europeos, precedido por una nota enviada por Matienzo -presidente del DNT- al Ministro del interior, en la que se fundamentaba la necesidad de una ley en este sentido $\left(B D N T \mathrm{n}^{\circ} 2,1907\right.$, $\mathrm{p}$. 161).

${ }^{20}$ BDNT n $^{\circ} 2,1907$, pp. $157-160$.

21 Ídem, p. 179. A mediados de 1908, la tarea de recaudar información continuaba y en el Boletín $n^{\circ}$ 6 de septiembre de ese año se puede leer una nota enviada por Matienzo al Ministerio del Interior, solicitando que éste dispusiera que la Intendencia municipal de la Capital enviara de manera mensual al DNT los datos relativos a las enfermedades de los obreros que se hubieran asistido en los hospitales de la dependencia del Ministerio, de acuerdo a los formularios elaborados por el Departamento (rama de industria, edad, sexo, nacionalidad, oficio, diagnóstico, tiempo de asistencia, resultado de ella, naturaleza de la incapacidad y clase de establecimiento industrial o comercial en que se haya adquirido la enfermedad). También en este Boletín se publicó la nota enviada por Matienzo al director general del Registro Civil de Capital pidiendo que se tomara nota del oficio de los obreros cuya defunción se registrara en los libros de esa repartición (recién en el Boletín número 30 de 1915 aparecerían detalladas las profesiones de los fallecidos en la Ciudad de Buenos Aires entre 1910 y 1913, según año, sexo, edad y agrupación de enfermedades) y otra enviada al director general de estadística municipal, solicitándole el envío mensual al DNT de una planilla en la que constara la edad, sexo, causa de la muerte y profesión de los fallecidos. (BDNT $n^{\circ}$ 6, 1908, pp. 425-426).

22 Gracias a una aclaración aparecida años más tarde, se puede saber que por lesión "leve" se entiende una lesión curable en 15 días a juicio del médico que intervenía, y "grave" cuando exigía mayor tiempo (BDNT n³0, 1915, p. 209). 


\section{En reclamo de un resarcimiento}

60 y más), el estado civil de los mayores de 14 años ${ }^{23}$, y los totales de éstas clasificaciones $^{24}$ A partir del Boletín siguiente, publicado tres meses después, se incorporó información sobre las causas, según profesiones y tipo de accidente (mortal o no) ${ }^{25}$. Este detalle de las causas se repetiría en los sucesivos Boletines, hasta el número 19 de diciembre de 1911 inclusive, después del cual cambiaría la manera de agrupar esta información ${ }^{26}$. Los cuadros estadísticos agrupados por profesión, daño, edad y estado civil continuaron publicándose, aunque detallando más profesiones, especificando la presencia de mujeres y en algunos casos incorporando la columna "sin datos". Recién a mediados de 1910, en el Boletín número 13, se agregarían a este cuadro las columnas de días y horas de los accidentes (esta última dividida en 7 a 9 am, 9 a 11, 1 a 3 pm, 3 en adelante y "sin datos") 27.

En el primer Boletín de 1909 (número 8) se publicó un resumen de los accidentes de trabajos ocurridos durante 1908 en la Ciudad de Buenos Aires, agrupados según profesión y detallando el bimestre del año en el que se habían producido, el total y su proporción por mil, lo cual dejaba ver cuáles fueron los gremios que más accidentes habían sufrido. Este resumen volvería a aparecer durante los años sucesivos, agregando la comparación de las cifras de los distintos años28. En Boletines siguientes también comenzarían a compararse los cuadros de accidentes entre distintos años.

A partir del último Boletín de 1909 (número 11), se incorporó información sobre accidentes de trabajo ocurridos en la Ciudad de Buenos Aires y otros puntos del país, suministrados por algunas de las más importantes compañías aseguradoras. Al respecto, se aclaraba que por la falta de disposiciones legales que obligaran a denunciar los accidentes, la totalidad de los mismos era imposible de conocer. Por eso, para mejorar y ampliar la estadística suministrada por la Policía,

\footnotetext{
23 Más adelante esta distinción desaparecería y la columna sería de "Estado Civil". También la columna de edad cambiaría su división a partir del último Boletín de 1909 (de 10 a 16 años, de 17 a 20, de 21 a 30 , de 31 a 40 , de 41 a 50, de 51 a 60 y 61 y más).

${ }^{24} B D N T \mathrm{n}^{\circ} 2,1907$, pp. 180-181. En la columna correspondiente a la profesión "peón jornaleros", fila "20 a 30 años", al lado del número 34 que indicaba la cantidad de accidentes ocurridos a los profesionales de esta edad, figura un asterisco que conduce a una nota al pie en la que se lee: "En esta cifra figuran dos mujeres, las únicas afectadas por accidentes del trabajo".

${ }^{25}$ En este número sólo se detallaban las causas de los accidentes ocurridos durante el mes de octubre de 1907.

${ }^{26}$ A partir del Boletín número 24 de 1913, las causas aparecieron detalladas según "grupos", por ejemplo "motores y generadores", "calderas a vapor", "caídas de andamios, escaleras", etc. y luego se especificaba el número de accidentes mortales, graves y leves para cada grupo de causas y se publicaba un cuadro con esta misma información detallada según profesión.

${ }^{27}$ A principios de 1911, en el resumen de los accidentes de trabajo ocurridos entre 1907 y 1910, se establecía que a partir de la incorporación del día y la hora de los accidentes a las estadísticas se podía saber que el mayor número de accidentes ocurría el Sábado y el horario que más infortunios registraba era el "de 3 en adelante" (BDNT n 16, 1911, p. 186).

${ }^{28}$ A partir del Boletín número 16 de 1911, al resumen de datos sobre accidentes ocurridos durante el año anterior, se agregó un nuevo cuadro en el que se establecía la relación entre el número de accidentes y la población de cada gremio -tomada del censo Municipal de 1909-, dejando ver cuáles eran los gremios que habían sufrido más accidentes en proporción a su cantidad de obreros. (BDNT $\left.\mathrm{n}^{\circ} 16,1911, \mathrm{p} .193\right)$.
} 


\section{Florencia D'Uva}

el DNT informaba que había recurrido a otras fuentes "buscando nuevas cifras en el registro de los casos denunciados a las compañías que toman a su cargo el seguro obrero"29. A partir de ello, según afirmaba el Boletín, no sólo se ampliaban los datos consignados hasta el momento sino que también se conocía la extensión que estaba adquiriendo la práctica de asegurar a los trabajadores contra los riesgos del trabajo ${ }^{30}$. Así, a partir de mediados de 1910, comenzó a publicarse un cuadro con los accidentes de trabajo ocurridos a obreros asegurados, clasificados según profesión, daño recibido (temporal, permanente o mortal ${ }^{31}$ ), edad y día. A mediados de 1911, en el Boletín número 17, se mencionaba el ascenso del seguro obrero y se publicaban varios cuadros que comparaban los seguros en todo el país entre 1907 y 1910, detallando el número de pólizas vigentes, la cantidad de obreros asegurados, el valor del salario, el número de siniestros ocurridos y de siniestros liquidados y el valor de éstos últimos expresado en pesos. En el Boletín siguiente, se reiteraba el crecimiento de los seguros contra accidentes ${ }^{32}$ y se remarcaba que los accidentes ocurridos en la ciudad de Buenos Aires durante el primer semestre de 1911 a obreros asegurados casi triplicaban a los constatados oficialmente por el DNT33.

El desarrollo y crecimiento de los seguros fue remarcado en reiteradas oportunidades por los Boletines del DNT. En el Boletín de principios de 1914, un informe elaborado por la División de Estadística establecía una comparación del seguro entre 1907 y 1913, en la que se evidenciaba el aumento "constante y proporcional en todos los factores sometidos a la observación estadística"34 (número de compañías aseguradoras, de pólizas en vigor, de obreros asegurados, etc.). Destacaba que el setenta y cinco por ciento del seguro obrero estaba

\footnotetext{
${ }^{29} B D N T \mathrm{n}^{\circ} 11,1909$, p. 576.

30 Ídem.

${ }^{31}$ Esta clasificación difería de la que el DNT venía haciendo (en base a los datos suministrados por la Policía) y no establecía si el siniestro había producido la inhabilitación total o parcial. Al respecto, en 1915 el Boletín aclaraba "ante esta dualidad, y la pobreza de datos originarios en lo que se refiere a la clasificación del daño, inevitables por ahora, se producirá alguna dificultad para el estudio de ciertos aspectos de la materia". Por ello, para el futuro, la División de Estadística "ha resuelto suprimir toda clasificación objetiva, adoptando las de "temporal" y "permanente" para los dos órdenes de investigaciones y completar esta a fin de poder distinguir en los casos de consecuencia permanente, si se ha producido una invalidez total, inhabilitando al obrero para el trabajo, o parcial, reduciendo su capacidad. En este último caso, deberá poderse clasificar la invalidez parcial en una serie de categorías de acuerdo con el carácter del daño para lo que se tratará de establecerlas en armonía con el criterio adoptado para la clasificación de indemnizaciones" $\left(B D N T \mathrm{n}^{\circ} 30,1915\right.$, p. 209).

${ }^{32}$ Asimismo, se remarcaba la participación de la mujer en los beneficios del seguro, contando que se habían liquidado 63 seguros para trabajadoras durante el primer semestre de $1911 B D N T \mathrm{n}^{\circ} 18$,

1911, p. 669).

$33 B D N T \mathrm{n}^{\circ}$ 18, 1911, p. 671. Esto mismo se señalaba en el Boletín número 24: "Si estudiamos algo más prolijamente la estadística de accidentes consignados por las compañías de seguros, necesitamos confesar, que los datos suministrados por la policía de la capital al Departamento, no son completos, y que la suma a que alcanzan los accidentes del trabajo es triple mayor que los que consigna la policía. La mayoría de los accidentes leves ocurridos en los talleres, se escaparon de la consideración de la policía. Los obreros, los que sufrieron accidente del trabajo de menor importancia no lo comunican a nadie, curándose en su casa $\left(B D N T \mathrm{n}^{\circ} 24,1913\right.$, p. 692).

${ }^{34} B D N T \mathrm{n}^{\circ} 29,1914$, p. 92.
} 


\section{En reclamo de un resarcimiento}

concentrado en la Capital Federal, en donde más de la mitad de la población industrial se encontraba asegurada ${ }^{35}$. Con respecto a las causas de este fenómeno, el Boletín afirmaba que el crecimiento de los seguros podía deberse a la conveniencia de los patrones en evitar las consecuencias de las demandas judiciales (lo cual, de ser cierto, demostraba que la legislación establecía directa o indirectamente la obligación de los empleadores de indemnizar a los obreros de los daños que sufrieran en el trabajo). Otra causa, sugería, podía ser el reconocimiento de los patrones de su responsabilidad moral, no ya legal, de indemnizar a sus obreros accidentados ${ }^{36}$. Luego de analizar la situación, concluía:

la causa del seguro espontáneo (...) obedece a la convicción de los patrones de que tienen el deber de indemnizar en los casos de accidentes y que cumplen lealmente con ese poder. Esto indica que la sociedad argentina ha incorporado a sus principios sociales el criterio jurídico más moderno en la materia, adelantándose a sus leyes al aceptar el seguro obrero"37.

Esta afirmación invita a pensar en las complejidades que existen en las prácticas sociales que anteceden a las leyes. El objetivo de este trabajo es justamente examinar, a partir del análisis de algunas demandas judiciales, cómo desde antes que existiera una ley se fueron gestando prácticas y acciones que buscaban resolver los problemas emanados de los accidentes de trabajo.

Ahora bien, la información estadística confeccionada por el DNT a lo largo de sus Boletines permite realizar un estudio cuantitativo de los accidentes de trabajo así como advertir cuáles fueron los datos que sus integrantes consideraron importante conocer (y cómo éstos fueron cambiando) para construir un panorama lo más completo posible de la realidad encarnada por los accidentes. Aún así, esta información no alcanza para cumplir el propósito de este artículo: rastrear las demandas de derechos que realizaron los propios trabajadores y sus familiares. Para llegar allí, es preciso volver sobre los fallos que los funcionarios del DNT decidieron publicar en sus boletines en su afán de conocer la jurisprudencia argentina en materia de accidentes de trabajo. Una lectura a contrapelo de los

\footnotetext{
35 Ídem. Durante estos años, en la Ciudad de Buenos Aires existieron varias compañías aseguradoras que funcionaban bajo la forma de seguro colectivo pagado por el patrón en favor de sus obreros. En general, los reglamentos, además de indicar los procedimientos necesarios para el cobro de la indemnización, establecían una tabla de recompensas según el tipo de daño recibido. En el BDNT n`18 del año 1911 se reproducen las clausulas del contrato de una de las principales Compañías del momento. Asimismo, resulta sugestivo el hecho de que, según lo anunciaba la UIA en un informe enviado al DNT, aun en los casos en los que no se contara con un seguro, muchas empresas afirmaban indemnizar a los obreros ya sea cubriendo los gastos de asistencia médica y abonando el salario durante el tiempo de inhabilitación, o indemnizando en igual porcentaje que las compañías en el caso de inhabilitación total o parcial permanente $\left(B D N T \mathrm{n}^{\circ} 2,1907\right.$, p. 159).

${ }^{36} B D N T \mathrm{n}^{\circ} 29,1914, \mathrm{p} .92$.

37 Ídem, p. 94. De hecho, ya en 1907, en respuesta a la información solicitada por el DNT al respecto, la UIA notificaba sobre la conformidad de los industriales con las compañías aseguradoras y agregaba que estarían de acuerdo con una ley, siempre y cuando no fuera demasiado onerosas para ellos $\left(B D N T \mathrm{n}^{\circ} 2,1907\right.$, p. 158 y 160$)$.
} 


\section{Florencia D'Uva}

mismos permite conocer algunas de las aspiraciones y formas de proceder de quienes decidían iniciar una demanda en la Justicia para reclamar lo que consideraban un derecho.

\section{Los trabajadores ante la Justicia.}

Como se adelantó en la introducción de este artículo, en la Argentina de principios de siglo XX fueron frecuentes las demandas judiciales iniciadas por trabajadores accidentados, o sus familiares, para reclamar una indemnización. Iniciar una demanda judicial era un acto de resistencia que implicaba arriesgar tiempo y dinero, sin tener la certeza de que el resultado sería el esperado. Los demandantes debían desarrollar estrategias que les permitieran argumentar lo justo del reclamo, demostrando que eran merecedores de una indemnización. En el despliegue de estas estrategias se ponían en juego nociones propias sobre el derecho y lo justo que pretendían ser reconocidas por la Justicia formal.

Hasta 1915, no existía el reconocimiento del "riesgo profesional" (es decir, del riesgo inherente al desempeño del trabajo), por lo cual el trabajador debía demostrar que el accidente era imputable a culpa o negligencia del patrón para el que trabajaba ${ }^{38}$. Para ello, podía apelar a los artículos 907, 1109, 1113 y 1133 del Código Civil. Estos disponían que en casos de hechos involuntarios que causaran daño a otros, el autor del hecho debía indemnizar solo si el hecho se hubiera producido por su culpa o negligencia o si por resultado del mismo se hubiera enriquecido. Esto se extendía a los daños causados por los que estuvieran bajo su dependencia, o por las cosas de que se sirviera, o que tuviera a su cuidado.

En la introducción de este artículo cité el caso de José Orlando, un herrero accidentado que mediante una demanda judicial logró conseguir una indemnización. Al analizar el relato del demandante, éste remarcaba que el accidente se produjo cuando, tras recibir la orden de bajar al sótano, "perdió pie" en la escalera movible a causa de haberse pegado en el tirante de hierro que la atravesaba ${ }^{39}$. Según Orlando, el accidente era consecuencia de las malas condiciones en las que se encontraba la entrada al subsuelo y por ello, había acudido a su empleador, Enrique Fynn, solicitándole una indemnización para reparar el daño sufrido (amputación de una pierna). Según declaraba el demandante, éste había prometido indemnizarlo aunque por un tiempo sólo podría darle trabajo. El herrero continuó trabajando para Fynn, percibiendo un salario significativamente menor y sin conseguir la indemnización acordada, pese a las gestiones realizadas. Por ello, decidió recurrir a la Justicia a reclamar un resarcimiento acorde a la lesión recibida, que según él lo imposibilitaba para toda la vida, hecho que resultaba tanto más grave al ser "padre de cuatro criaturas" 40 . En su argumento señalaba la responsabilidad del empleador (al no tener la entrada al

\footnotetext{
${ }^{38} B D N T \mathrm{n}^{\circ} 20,1912$, p. 36.

${ }^{39}$ BDNT n $^{\circ} 16,1911$, p. 56.

40 Ídem.
} 


\section{En reclamo de un resarcimiento}

subsuelo en condiciones) la cual, según afirmaba, quedaba "consagrada expresamente" en los artículos 1105 y sus correlativos del Código Civil ${ }^{41}$. A partir de las declaraciones y de un informe pericial ordenado por el juez, se comprobó que las condiciones de entrada al subsuelo eran deficientes y riesgosas para quienes ejecutaran la bajada. Por ende, se evidenció la negligencia del demandado, que había permitido la instalación de un taller en un lugar de acceso difícil y peligroso sin tomar las medidas que fueran necesarias para prevenir accidentes ${ }^{42}$. Esta circunstancia era contemplada por los artículos 1109 y 1113 del Código Civil ya comentados. En base a esta disposición, el 21 de diciembre de 1909 el juez condenó al señor Fynn a indemnizar a su empleado.

En este caso se puede apreciar la estrategia del trabajador demandante para reclamar la indemnización, quien basó su argumento en demostrar que su empleador había sido negligente al no haber tomado los recaudos necesarios para prevenir un accidente en sus instalaciones, cuestión que estaba contemplada en los artículos 1109 y 1113 del Código Civil. Para reforzar su coartada, aclaraba que la acción que estaba realizando al accidentarse había sido ordenada por el patrón y hacía hincapié en su responsabilidad de ser padre de cuatro criaturas. Esto último puede haber sido parte de una estrategia premeditada del herrero, de situarse como proveedor de su hogar, garante de la subsistencia de su familia, lo cual además de poder ser contemplado por el juez, podía influir en la fijación del monto de la indemnización, en caso de que la hubiera.

Probar la culpa o negligencia del patrón en la Justicia no siempre resultaba fácil. Según afirmaba un informe elaborado por Federico Figueroa en junio de 1912, publicado en el Boletín del DNT de ese mismo año, en los pocos juicios iniciados hasta 1905 aproximadamente, "el patrono demandado, no solo mostraba que el caso era enteramente ajeno a toda previsión (...) sino que, gracias a la fácil adquisición de testigos, llegaba hasta probar que en el accidente había existido negligencia o culpa del obrero"43. Además, exponía que la mayoría de los accidentes eran resultado del "riesgo profesional", es decir, de hechos fortuitos, inevitables, resultado de la misma actividad laboral, en los que no existía culpa o negligencia del patrón ni del obrero. Como consecuencia, Figueroa afirmaba que el trabajador accidentado se veía forzado a resignarse ante el daño sufrido o a recibir una pequeña cantidad de dinero ofrecida por el patrón a título de caridad, con el fin de evitar las molestias de una posible demanda judicial ${ }^{44}$.

Ese mismo informe fechaba el cambio de esta situación en 1905 cuando, según advertía, varios jueces comenzaron a contemplar la precaria situación de los obreros así como los crecientes peligros del maquinismo, encuadrando implícitamente sus sentencias dentro del principio del riesgo profesional. El argumento era el reconocimiento de que la explotación industrial implicaba

\footnotetext{
41 Ídem, p. 57.

42 Ídem, pp. 58-59

${ }^{43} B D N T \mathrm{n}^{\circ} 20,1912$, p. 36.

44 Ídem.
} 


\section{Florencia D'Uva}

riesgos inevitables y muchas veces imprevisibles, cuyas consecuencias debía soportar el beneficiario ${ }^{45}$. Este informe citaba un fallo del juez Ernesto Quesada, en mayo de 1908, como punto de inflexión por haber sido el primero en contemplar de manera clara el principio del riesgo profesional ${ }^{46}$. La causa había sido iniciada por Carmelo E. Olivera contra los señores José Moreyra y José Othacehé a raíz del accidente ocurrido seis años atrás a su hijo, contratado en las fábricas de tejidos que poseían los señores. Según exponía Olivera, el accidente que arrancó la mano derecha al menor se había debido exclusivamente a la imprudencia e imprevisión de aquellos que pusieron en manos de un menor inexperto el manejo de una maquina, sin advertirle de su mecanismo, y sin siquiera estar informados respecto del asentimiento de sus padres para tal trabajo ${ }^{47}$. A partir de ello, el demandante invocaba el derecho dispuesto en los artículos 1109 y 1113 del Código Civil que, como ya se mencionó, prescribían que "el que ejecuta un hecho que por su culpa o negligencia, ocasionara un daño a otro está obligado a la reparación del perjuicio, y que la obligación del que ha causado un daño, se extiende a otros daños que causaren los que están bajo su dependencia, por los casos de que se sirve ó que tiene a su cuidado"48. Por su parte, los demandados no discutían el derecho que invocaba el padre del menor accidentado, sino que intentaban desligarse de su responsabilidad, argumentando que el niño había sido contratado por pedido del padre, y que el trabajo que se le había encomendado era sencillo y no implicaba ningún peligro, por lo cual el accidente era exclusivamente imputable al menor ${ }^{49}$. En la sentencia, Quesada ratificó el argumento de la parte demandante que había denunciado la imprudencia y negligencia en la que había incurrido el capataz al ordenar a un menor inexperimentado manejar (o limpiar) una máquina peligrosa con la que no estaba familiarizado. El juez expuso que de ninguna manera el accidente era imputable al menor, ya que éste no tenía porqué tomar precauciones debido a que ignoraba el peligro al que se encontraba expuesto ${ }^{50}$. Asimismo, señaló que la negligencia e imprudencia se hacían más evidentes al considerar que en un primer momento los demandados habían accedido al pedido extrajudicial que les había hecho el padre del menor, pero sin haber podido ponerse de acuerdo en el monto, éste decidió iniciar su reclamo por vía judicial ${ }^{51}$ A partir de estas consideraciones, Quesada pronunció el fallo que consagraba de la manera más clara hasta ese momento el principio del riesgo profesional. Condenando a los demandados a pagar una indemnización, afirmaba:

Que no incumbe al obrero la obligación de probar la culpa, sino que tal prueba invertidos los términos, corresponde al patrono. Esto sentado, en las

\footnotetext{
45 Ídem, p. 41.

46 Ídem, p. 35.

47 Ídem, p. 47.

48 Ídem.

49 Ídem.

50 Ídem, p. 48.

51 Ídem.
} 


\section{En reclamo de un resarcimiento}

responsabilidades subsidiarias por accidentes del trabajo, no hay porque ni para que atender á la responsabilidad ó intención del agente inmediato del hecho; se atiende tan solo al hecho que causa el daño, pues el patrono responde de los hechos de la industria, sean ellos producidos por obreros, por las cosas que forman parte de la industria ó intervienen en ella, sea por vicio propio ó riesgo de la cosa, sean hechos de la naturaleza ó que resulten de la industria misma, siempre que el daño ocurrido al obrero ó dependiente no hubiera sido sino por su culpa ó voluntad 52.

Este fallo invertía la carga de la prueba, al dictaminar que correspondía al patrón demostrar la culpa o negligencia del obrero para evitar la indemnización. La sentencia de Quesada adquiere más sentido cuando se sitúa en el contexto de la Argentina de principios de siglo, en la que el trabajo, y particularmente el de los menores, comenzaba a convertirse en una fuente de problemas e interpretaciones encontradas. En este escenario, diversos grupos -como el Partido Socialista y ciertas organizaciones gremiales- formularon reclamos para mejorar la situación de los trabajadores considerados más vulnerables, como los menores y las mujeres. Parte de la elite gobernante compartía esta preocupación, la cual llegó al Congreso en donde, tras varias discusiones, en 1907 se sancionó la ley 5.291 de trabajo de mujeres y menores ${ }^{53}$.

En septiembre de 1909, en otro caso que involucraba a un menor y al juez Ernesto Quesada, Antonio Messina ganó el juicio iniciado contra la empresa Medici y Lacaze por indemnización de daños ocurridos a su hijo Vicente Messina. Según narró su padre durante el juicio, Vicente era marinero ocupado a bordo del patacho argentino "Beatriz Amanda P", en el que se encargaba de recibir y dirigir un cargamento de piedras de la misma empresa. Esta labor era realizada por medio de una grúa fija en la cubierta de un pontón ${ }^{54}$, propiedad de la empresa, atendida por empleados suyos, y bajo su dependencia, encargados de recibir y dar dirección á la carga conducida por la cadena de la grúa, hasta el lugar convenido para su depósito. Vicente estaba realizando esta tarea cuando en uno de los viajes de la carga, se rompió la cadena de fierro de la grúa, por lo que la gran piedra que estaba siendo transportada cayó sobre el menor, destruyéndole una pierna hasta la altura de la rodilla ${ }^{55}$. En la demanda iniciada, el padre basaba su reclamo en demostrar la mala calidad de la cadena, incapaz de aguantar las toneladas de peso de las piedras que estaban siendo transportadas. Con ello, pretendía demostrar la negligencia de la empresa al utilizar un elemento de mala calidad, o de una capacidad insuficiente, para realizar una tarea que involucraba materiales pesados que podían lastimar a sus empleados. Al pronunciar la sentencia, el juez consideró que el demandante había ofrecido pruebas suficientes sobre la responsabilidad de

\footnotetext{
52 Ídem, p. 44.

53 José Panettieri. Las primeras leyes obreras, Buenos Aires, CEAL, 1984.

54 Barco con su parte anterior de forma redonda, que se usa para pasar ríos, construir puentes y limpiar el fondo de un río o un puerto con ayuda de máquinas.

$55 B{ }^{2} N$ n $^{\circ} 20,1912$, p. 41.
} 


\section{Florencia D'Uva}

la empresa por las consecuencias del accidente "por lo que su obligación de reparar el daño causado surge no sólo del artículo 1133 del código civil, sino del principio consagrado por los artículos 1109 y 1113 del mismo código"56. Si bien no se demostraba la culpa de la empresa, se deducía su negligencia por no haber controlado el estado de la cadena. Al igual que en el caso anterior, se remarcaba que la negligencia resultaba más evidente al advertirse que los mismos demandados habían accedido en un principio á la reclamación extrajudicial que les había hecho el padre de la víctima no habiéndose podido poner de acuerdo en el monto de la indemnización exigida, circunstancia que motorizó el inicio de la demanda en la Justicia ${ }^{57}$. Este hecho, que parecía ser una práctica bastante extendida en estos casos, demostraba el reconocimiento de la falta por parte de la empresa, lo cual reforzaba la idea de que el menor accidentado no había incurrido en ninguna imprudencia. Como demuestran estos dos casos, los demandantes (padres de los trabajadores menores accidentados) basaban su reclamo en demostrar la falta de la parte demandada, ya sea por haber dado una orden imprecisa, o por no haber controlado el estado de las herramientas o materiales de trabajo, para así encuadrar su caso dentro de lo contemplado por los artículos ya citados del Código Civil.

Era frecuente que un familiar iniciara la demanda, ya sea porque los accidentados eran menores (como se vio en los casos anteriores) o porque el accidente había resultado mortal. El 17 de noviembre de 1904, un guarda tren del Ferrocarril Central Argentino, Ángel Sarmiento, falleció a raíz de un accidente producido, según narró después su esposa, mientras se encontraba desempeñando una tarea que no le correspondía, ordenado por sus superiores debido a la falta de personal. Su viuda, Dolores Gómez de Sarmiento, inició una causa judicial contra la empresa, por sí y a nombre de sus hijos, para obtener una indemnización por los daños y perjuicios sobrevenidos por la muerte de su esposo ${ }^{58}$. En la demanda, la viuda atribuía la responsabilidad del hecho a la culpa o negligencia de la empresa que había trasgredido lo dispuesto por la Ley General de Ferrocarriles Nacionales, al no tener el número de empleados suficientes para asegurar la regularidad del servicio y evitar los peligros. Debido a esta circunstancia, según exponía la mujer, era frecuente que su esposo se ocupara en funciones que no le correspondían, como la de enganche y desenganche de vagones, que desempeñaba cuando falleciós9. Así, la viuda basaba su reclamo en el hecho de que la empresa había incumplido lo establecido por el artículo 11 de la Ley General de Ferrocarriles, que disponía que "toda empresa deberá tener en las estaciones, en los trenes y en todo el trayecto del camino de día y de noche, desde que empiece hasta que termine el movimiento diario, el número de empleados que fuese necesario para que el

\footnotetext{
56 Ídem, p. 42.

57 Ídem, p. 48.

${ }^{58} B D N T \mathrm{n}^{\circ} 24,1913$, p. 506.

59 Ídem, p. 507.
} 


\section{En reclamo de un resarcimiento}

servicio se haga con regularidad, y sin tropiezo ni peligro de accidentes"60. A su vez, a partir de la declaración de dos testigos presenciales se confirmaba que no había ningún empleado encargado de avisar que los vagones que habían sido largados iban a juntarse con los otros vagones parados que el guarda tren estaba enganchando al furgón, por lo cual éste no tuvo tiempo de reaccionar y fue aplastado, muriendo prácticamente en el acto ${ }^{61}$. De las declaraciones de los testigos también se desprendía que en la estación Ballesteros, donde tuvo lugar el incidente, no había empleados especialmente ocupados en las tareas de maniobras, por lo cual era normal que los guarda trenes se ocuparan de realizarlas, además de desempeñarse como guardas ${ }^{62}$. Esta circunstancia era únicamente responsabilidad de la empresa, ya que según lo dispuesto por el artículo 65 de la mencionada Ley de Ferrocarriles, "Es deber de las empresas velar porque todos sus empleados sean diligentes e idóneos. Su responsabilidad hacia los pasajeros y cargadores por daños resultantes de faltas de sus empleados, se extiende a todos los actos ejecutados por éstos en el desempeño de sus funciones. En casos de accidentes, incumbe a las empresas probar que el daño resulta de caso fortuito o de fuerza mayor"63. El artículo 83 ampliaba: "Si el causante del accidente fuera empleado de la empresa, ésta responderá por los daños y perjuicios causados". En base a la comprobación de la denuncia de la viuda, que acusaba a la empresa de haber trasgredido los artículos de la Ley General de Ferrocarriles, el 11 de julio de 1911, el juez condenó a la empresa Ferrocarril Central Argentino a pagar a la esposa e hijos del guarda Ángel Sarmiento una suma estipulada en base a la edad de la víctima y el sueldo que percibía como guarda64. Casi un año después, la Cámara de Apelaciones confirmaba el fallo, afirmando que la responsabilidad de la empresa demandada emanaba no solo de los artículos ya citados de la Ley de Ferrocarriles sino también de los artículos 1109 y 1113 del Código Civil65. En este caso, a diferencia de los anteriores, por tratarse de un trabajador de un ferrocarril, entró en juego una ley elaborada especialmente para regular la actividad ferroviaria, eje fundamental de la economía nacional de este período. Gracias a ello, la viuda del guarda tren tuvo a su disposición más herramientas para demostrar la falta de la empresa, amparándose en algunos artículos de la Ley General de Ferrocarriles, más allá de ciertas disposiciones presentes en el Código Civil que podrían haberse encuadrado en su argumento.

Éste no fue el único caso en que se invocó La Ley de Ferrocarriles para reclamar una indemnización. Tras el accidente ocurrido a su hijo en octubre de 1906, Josefa Arce inició una demanda contra la empresa de navegación a vapor Nicolás Mihanovich, en la que Emilio Arce trabajaba. Exigía una indemnización por

\footnotetext{
60 Ídem.

61 Ídem, p. 508.

62 Ídem.

63 Art. $\mathrm{n}^{\circ} 65$ de la Ley General de Ferrocarriles Nacionales, disponible en http://www.adecua.org.ar/legislacion.php?ver=servicios 2873

${ }^{64} B D N T$ n $^{\circ} 24,1913$, p. 509.

65 Ídem, p. 510.
} 


\section{Florencia D'Uva}

el fallecimiento de su hijo, producido como consecuencia de la explosión de la caldera del vapor "Tesoro". En su declaración, la mujer afirmaba "que perteneciendo dicho vapor a la empresa demandada, y siendo exclusivamente imputable a ella la explosión aludida, la acción quedaba fundada con la sola exposición del hecho ante las proscripciones de los artículos 1067, 1068, 1109, 1110 y 1113 del código civil, y las disposiciones de la ley 2873, cuyo artículo 101 es aplicable al caso"66. El artículo 101 de esta ley disponía que "Mientras se dicte una ley especial sobre transporte por agua, éstos se regirán por las disposiciones de la presente ley que les fueren aplicables"67. Según la demandante, la mera acción de exponer el hecho bastaba para demostrar la imputabilidad de la empresa, ya que esta quedaba establecida por ciertos artículos del Código Civil, así como por la Ley General de Ferrocarriles Nacionales. Así lo contempló el juez, que el 10 de agosto de 1910 condenó a la empresa a indemnizar a la demandante, quien, al igual que en el caso anterior, había logrado probar la culpa o negligencia de la empresa gracias a ciertos artículos del Código Civil, así como a lo dispuesto por la Ley de Ferrocarriles, cuyos artículos eran aplicables al transporte marítimo.

A pesar de los fallos dictados durante estos años que condenaron a las empresas o patrones a indemnizar a sus trabajadores accidentados, los que iniciaron una causa no siempre lograron demostrar la imprudencia o negligencia de los demandados. El 29 de mayo de 1909, Genaro Freire, peón de la Cervecería Palermo, se accidentó mientras se encontraba almacenando botellas en uno de los depósitos de la empresa, cuando una de ellas explotó hiriéndolo gravemente en su mano derecha. Como consecuencia, Freire afirmaba haber perdido gran parte de la sensibilidad de la mano, lo cual le dificultaba el movimiento de sus dedos y lo imposibilitaba para hacer fuerza. Según exponía el peón, al comprobar su incapacidad para el trabajo, la Compañía demandada lo despidió, sin otorgarle ninguna indemnización. Luego del fracaso de las gestiones realizadas para conseguirla, Freire decidió iniciar una demanda en la Justicia. Según alegaba, la Cervecería era culpable del accidente por haber colocado la cerveza de tal modo que su fermentación produjo la explosión, hecho que no podía ser evitado ni previsto por él. Citaba el artículo 1109 y concordantes del Código Civil que establecían el derecho que lo asistía para entablar la demanda. Como resarcimiento pedía una indemnización y el pago de una cirugía indispensable para volver a tener la mano en condiciones para trabajar68. Por su parte, la empresa declaró que Freire se encontraba asegurado al momento del accidente, y que había sido atendido por un médico que dada la poca importancia de la lesión, le había dado de alta luego de efectuarle una curación. Aclaraba que el médico de "La Industrial", que aseguraba a los trabajadores de la Cervecería, había dictaminado que éste se curaría dentro de los 13 a 17 días. También informó que

\footnotetext{
${ }^{66} B D N T \mathrm{n}^{\circ} 20,1912$, p. 43.

${ }^{67}$ Art. $n^{\circ} 101$ de la Ley General de Ferrocarriles Nacionales, disponible en http://www.adecua.org.ar/legislacion.php?ver=servicios 2873

${ }^{68} B D N T \mathrm{n}^{\circ} 19,1911$, pp. 812-813.
} 


\section{En reclamo de un resarcimiento}

durante los 31 días que Freire no pudo trabajar, se le abonó medio jornal, de acuerdo con los estatutos del seguro y que al volver al trabajo, el peón se hizo reconocer por dos médicos del "Círculo de Obreros" que le recomendaron una operación que la Cervecería, asesorada por su médico, no consideró necesaria, ofreciéndole la máxima indemnización parcial (correspondiente al 25 por ciento de reducción de su capacidad funcional) que Freire rechazó6 ${ }^{9}$. En este caso, el juez manifestó que la aplicación del artículo 1109 expresada por el demandante, no resultaba clara ya que no había logrado probar la culpabilidad de la Compañía, debiendo atribuirse el accidente a una impericia o maniobra imprudente del damnificado ${ }^{70}$. Y agregaba que aun en el caso de que hubiera habido culpabilidad de la empresa, el peón había sido compensado por los perjuicios sufridos al haber continuado recibiendo su jornal, aunque reducido, durante los días en los que estuvo imposibilitado para trabajar, y al haber sido admitido a continuar como peón del establecimiento, con igual sueldo que antes del accidente ${ }^{71}$. Con este argumento, el 11 de junio de 1910, el juez rechazó la demanda. Este caso muestra los límites que tenía la práctica de apelar a los artículos del Código Civil, ya que no siempre los trabajadores lograban demostrar la culpa o negligencia de la empresa. En parte esto era así porque muchos de los accidentes eran resultado del "riesgo profesional" que, hasta la sanción de la Ley de Accidentes de Trabajo en 1915, no estaba contemplado, y por ende no podía invocarse para imputar al patrón.

\section{Balance.}

El análisis de las demandas judiciales permitió rastrear algunas de las estrategias que los trabajadores pusieron en práctica para reclamar lo que consideraban un derecho, así como conocer qué nociones sobre lo justo aparecen implicadas en las mismas. Con respecto a las primeras, en los distintos juicios citados se vio que los trabajadores buscaron demostrar la culpa o negligencia de los demandados, apelando a varios artículos del Código Civil (907, 1109, 1113, 1133) así como a otras leyes que contemplaban la especificidad de ciertas profesiones, como la de los ferroviarios o marítimos. A su vez, pudo advertirse cómo los trabajadores elegían remarcar ciertos hechos o circunstancias que consideraban que podían influir en la decisión final, tal como la gravedad del daño sufrido que impedía volver a realizar ciertas tareas, el haber recibido órdenes para realizar la acción que había desencadenado el accidente -que en algunos casos podía no corresponder con las tareas habituales para las que el trabajador estaba contratado-, el ofrecimiento de una indemnización por parte del patrón o empresa -que implicaba el reconocimiento de éstos de su culpa, falta o negligencia-, el ser

\footnotetext{
69 Ídem, p. 813.

70 Ídem, p. 814. En relación a esto es interesante remarcar que las declaraciones de dos peones de la cervecería fueron subestimadas por el juez, por tratarse de simples testigos presenciales del accidente, carentes de conocimientos técnicos sobre la causa de la explosión de la botella.

${ }^{71}$ BDNT n $^{\circ} 19,1911$, p. 815.
} 


\section{Florencia D'Uva}

padres o madres de familia numerosa, proveedores del hogar, menores de edad, entre otras situaciones que podían exponerse.

En relación a las nociones sobre lo justo, éstas aparecen implícitas en las demandas citadas, en las que los trabajadores buscaron demostrar la validez de su reclamo, apelando al Código Civil que los amparaba como ciudadanos. Desde el preciso instante en que se decidía iniciar una acción legal, quedaba claro que para los demandantes era esperable que existieran mínimas condiciones de seguridad e higiene en los lugares de trabajo, de las cuales los patrones o empresas se hicieran cargo, y que éstos se ocuparan de resarcir los daños y perjuicios ocasionados en caso de accidentes. En la mayoría de los casos se vio cómo en un primer momento las partes habían intentado realizar un arreglo (que podía consistir en una suma de dinero, o la cobertura de determinados tratamientos y gastos médicos) que una vez fracasado motivó el inicio de un reclamo judicial. Esto implicaba una concepción sobre las obligaciones y responsabilidades de los patrones por un lado, y los derechos de los trabajadores por otro. Durante los años previos a la sanción de la Ley de Accidentes de Trabajo en 1915, estas concepciones sobre las obligaciones y derechos fueron redefiniéndose no solo en la Justicia, sino también en los distintos lugares de trabajo, en el Parlamento, así como dentro de las variadas fuerzas políticas y partidarias de signo obrero y patronal.

Tener en cuenta las acciones emprendidas por los trabajadores que acudían a la Justicia devuelve agencia a un sector que en muchos análisis ha quedado relegado al papel de espectador pasivo de los cambios ideológicos y decisiones de los sectores gobernantes. A su vez, invita a pensar la ley como un cambio formal, lo cual no implica desmerecer los avances que ésta conllevó, pero si permite entenderla como una continuidad de ciertas prácticas que se venían desarrollando desde, al menos, diez años antes de su sanción. Apropiándose de ciertas leyes ofrecidas por el Estado, los trabajadores supieron hacer oír su voz en la Justicia y utilizaron el camino ofrecido por el mundo legal para intentar hacer cumplir lo que consideraban un derecho.

\section{Bibliografía.}

Eduardo A. Zimmermann.. Los liberales reformistas. La cuestión social en la Argentina 1890-1916. Buenos Aires, Editorial Sudamericana, Universidad de San Andrés, 1995.

Edward P. Thompson, Los orígenes de la Ley Negra. Un episodio de la historia criminal inglesa. Buenos Aires, Siglo Veintiuno editores, 2010.

Ernesto Isuar. Los orígenes conflictivos de la seguridad social argentina. Buenos Aires, CEAL, 1985.

Florencia D’Uva y Ludmila Scheinkman, “De lisiadas y tullidos. Trabajadoras y trabajadores ante la Ley de Accidentes de Trabajo de 1915". Ponencia presentada en el Congreso Latinoamericano de Historia de las Mujeres, Buenos Aires - San Juan, 2012a. 
"Rotos y mal parados: los trabajadores ante la sanción de la ley de Accidentes de Trabajo de 1915". Actas de las 3ras Jornadas Internacionales de Problemas Latinoamericanos: Movimientos Sociales, Estados y Partidos Políticos en América Latina: (re)configuraciones institucionales, experiencias de organización y resistencia. Publicación Electrónica, Mendoza, 2012b.

"La ley de Accidentes del Trabajo en

Argentina: la demanda de los trabajadores (1915)", ponencia presentada en las XIV Jornadas Interescuelas/Departamentos de Historia, Universidad Nacional de Cuyo, Mendoza, 2013.

Hernán Otero. Estadística y Nación. Una historia conceptual del pensamiento censal de la Argentina moderna (1869-1914). Buenos Aires, Prometeo, 2007.

Hilda Sábato. La política en las calles. Entre el voto y la movilización. Buenos Aires, 1862-1880. Buenos Aires, Editorial Sudamericana, 1998.

- Ciudadanía y formación de las naciones. Perspectivas históricas de América Latina. México, Fondo de Cultura Económica, 1999.

José Panettieri. Las primeras leyes obreras, Buenos Aires, CEAL, 1984.

Juan Suriano. La cuestión social en Argentina 1870-. 1943. Buenos Aires, La Colmena, 2000

"El mundo como un taller de observación. La creación del Departamento Nacional del trabajo y las influencias internacionales". Revista de Indias; vol. LXXIII, $\mathrm{n}^{\circ} 257,2013$.

Karina Ramacciotti. "De la culpa al seguro. La Ley de Accidentes de Trabajo, Argentina (1915-1955)”. Mundos do Trabalho, 3(5), pp. 266-284, 2011.

“ ¿Soldados del trabajo o ciudadanos? La Ley de Accidentes

de Trabajo en la Argentina, 1915-1955"; en Mirta Lobato y Juan Suriano (comp.). La sociedad del trabajo. Las instituciones laborales en la Argentina (1900-1955). Buenos Aires Edhasa, 2014.

Larissa R. Corrêa. A tessitura dos direitos: patrões e empregados na Justiça do Trabalho, 1953-1964. San Pablo, Editora Ltda., 2011.

Line Schjolden. "Sentencing the Social Question: Court-Made Labour Law in Cases of Occupational Accidents in Argentina, 1900-1915". Journal of Latin American Studies, $\mathrm{n}^{\circ}$ 41, pp. 91-120, 2009.

Lyman Johnson. "A lack of legitimate Obedience and Respect: Slaves and their Masters in the Courts of Late Colonial Buenos Aires". Hispanic American Historical Review, 87, (4), 2007.

Mirta Lobato y Juan Suriano (comp.). La sociedad del trabajo. Las instituciones laborales en la Argentina (1900-1955). Buenos Aires, Edhasa, 2014.

Silvana Palermo. "¿Trabajo masculino, protesta femenina? La participación de la mujer en la gran huelga ferroviaria de 1917"; en María Celia Bravo, (et al.). Historias de luchas, resistencias y representaciones. Mujeres en la Argentina, siglos XIX Y XX, Tucumán, EDUNT, 2007.

------. “Género y ciudadanía política: algunos apuntes en la agenda de investigación”. PolHis, $\mathrm{N}^{\circ} 7,1^{\circ}$ semestre de 2011.

Silvia Lara e Joseli Mendonça (et.al.). Direitos e Justicas no Brasil: ensaios de história social. Unicamp, Ed. Unicamp, 2006.

Valeria S. Pita. La Casa de las Locas. Una historia social del manicomio de mujeres. Buenos Aires 1852-1890. Rosario, Prohistoria, 2012. 